\title{
TEA Elicits Two Distinct Potentiations of Synaptic Transmission in the CA1 Region of the Hippocampal Slice
}

\author{
Eric Hanse and Bengt Gustafsson \\ Department of Physiology, University of Göteborg, S-413 90 Göteborg, Sweden
}

\begin{abstract}
Extracellular application of tetraethylammonium (TEA) has been shown to elicit a prolonged synaptic potentiation in the CA1 region of the hippocampus that is unaffected by NMDA receptor antagonists, but is blocked by antagonists to voltage-dependent calcium channels (Aniksztejn and Ben-Ari, 1991; Huang and Malenka, 1993). In the present study the relation between TEA-induced potentiation and NMDA receptor-dependent long-term potentiation (LTP) was investigated in the CA1 region of the hippocampal slice using extracellular recordings and picrotoxin to block $\mathrm{GABA}_{\mathrm{A}}-\mathrm{me}$ diated inhibition. Consistent with the finding of Huang and Malenka (1993), NMDA receptor-dependent LTP partially occluded the TEA-induced potentiation. However, this occlusion was abolished when the NMDA receptor antagonist D(-)-2-amino-5-phosphonopentanoic acid (D-AP5) was present during the application of TEA, indicating one component of TEA-induced potentiation that is induced via NMDA receptor channels and another component that is distinct from NMDA receptor-dependent LTP. In the presence of antagonists to voltage-dependent calcium channels (nifedipine or nifedipine/flunarazine) application of TEA induced a potentiation that was largely occluded by NMDA receptordependent LTP. In common with NMDA receptor-dependent LTP, the TEA-induced potentiation, elicited in the presence of antagonists to voltage-dependent calcium channels, was associated with a symmetrical increase of the field EPSP. On the other hand, the TEA-induced potentiation elicited in the presence of D-AP5 produced an increase of the field EPSP that did not include the early part of the initial slope. It is concluded that application of TEA can activate both NMDA receptor channels and voltage-dependent calcium channels, and that the potentiation associated with activation of voltage-dependent calcium channels is distinct from NMDA receptor-dependent LTP.
\end{abstract}

[Key words: long-term potentiation, hippocampus, CA1, synaptic plasticity, tetraethylammonium, NMDA receptor, voltage-dependent calcium channel, calcium]

Long-term potentiation (LTP) of synaptic transmission is generally evoked by a brief afferent tetanus, this high-frequency activation providing the necessary coincident pre- and postsyn-

Received Oct. 11, 1993; revised Jan. 19, 1994; accepted Feb. 24, 1994.

-This work was supported by the Swedish Medical Research Council (Project 05180), Kungliga Vetenskaps-och Vitterhets-Samhället and the foundations of Magnus Bergvall and Lars Hierta.

Correspondence should be addressed to E. Hanse, Department of Physiology, University of Götcborg, Medicinargatan 11, S-41390 Göteborg, Sweden.

Copyright (C) 1994 Society for Neuroscience $0270-6474 / 94 / 145028-07 \$ 05.00 / 0$ aptic activity to open postsynaptic NMDA receptor channels and allowing for calcium influx into the postsynaptic spine. The subsequent transient increase in calcium concentration locally in the postsynaptic spine is thought to be the trigger for LTP (Madison et al., 1991). Long-lasting potentiations of synaptic transmission can also be evoked by other means, for example by bath application of various drugs. An example of this is a transient application of the potassium channel blocker tetraethylammonium (TEA) (Aniksztejn and Ben-Ari, 1991). The TEA-induced potentiation is observed in the presence of antagonists to the NMDA receptor channel but is blocked by antagonists of voltage-dependent calcium channels (Aniksztejn and Ben-Ari, 1991; Huang and Malenka, 1993). These results may indicate that the NMDA receptor channel does not have a privileged role in supplying calcium for the induction of LTP, but that this calcium may be provided via activation of voltagedependent calcium channels (see also Grover and Teyler, 1991a). Alternatively, the TEA-induced synaptic potentiation may be distinct from the NMDA receptor-dependent LTP.

A recent study of TEA-induced potentiation reported a partial mutual occlusion between TEA-induced potentiation and the tetanus-induced one (Huang and Malenka, 1993). Whether the lack of full occlusion between the potentiations induced by tetanization and TEA, respectively, was due to unshared expression mechanisms or to the different induction conditions (bath application vs afferent tetanization), was left open by the authors. However, other studies using intense postsynaptic activation (Hess and Gustafsson, 1990), or application of NMDA (Asztely et al., 1991), have suggested the existence of mechanistically separate long-lasting synaptic potentiations in the CAl region.

The aim of the present study was to examine whether the potentiation elicited by TEA is equivalent to the NMDA reccptor-dependent LTP, or whether TEA elicits more than one potentiation process.

\section{Materials and Methods}

Experiments were performed on hippocampal slices prepared from 31 guinea pigs $(300-400 \mathrm{gm})$ as previously described (Gustafsson et al., 1989). A surgical cut was made between CA3 and CA1 to prevent epileptiform bursting. The slices were maintained at $30^{\circ} \mathrm{C}$, half submerged, in a constant flow $(2-2.5 \mathrm{ml} / \mathrm{min})$ chamber. The perfusion fluid contained (in $\mathrm{mM}$ ) NaCl, $124 ; \mathrm{KCl}, 4 ; \mathrm{CaCl}_{2}, 2 ; \mathrm{MgCl}_{2}, 2 ; \mathrm{NaHCO}_{3}$, 26; $\mathrm{NaH}_{2} \mathrm{PO}_{4}, 1.25$; glucose, 10 ; and gassed with $95 \% \mathrm{O}_{2}, 5 \% \mathrm{CO}_{2}$. In experiments where $\mathrm{GABA}_{\mathrm{A}}$-mediated inhibition was blocked by 100 $\mu \mathrm{M}$ picrotoxin the extracellular concentrations of calcium and magnesium wcre raiscd to $4 \mathrm{~mm}$ each. Field potentials were recorded with glass micropipettes (filled with $3 \mathrm{M} \mathrm{NaCl}$ ) in the apical dendritic layer of the CA1 region (stratum radiatum) and in the cell body layer. Two stimulation electrodes were positioned in the apical dendritic region on either side of the recording electrode to provide two independent afferent 


\section{Normal solution}
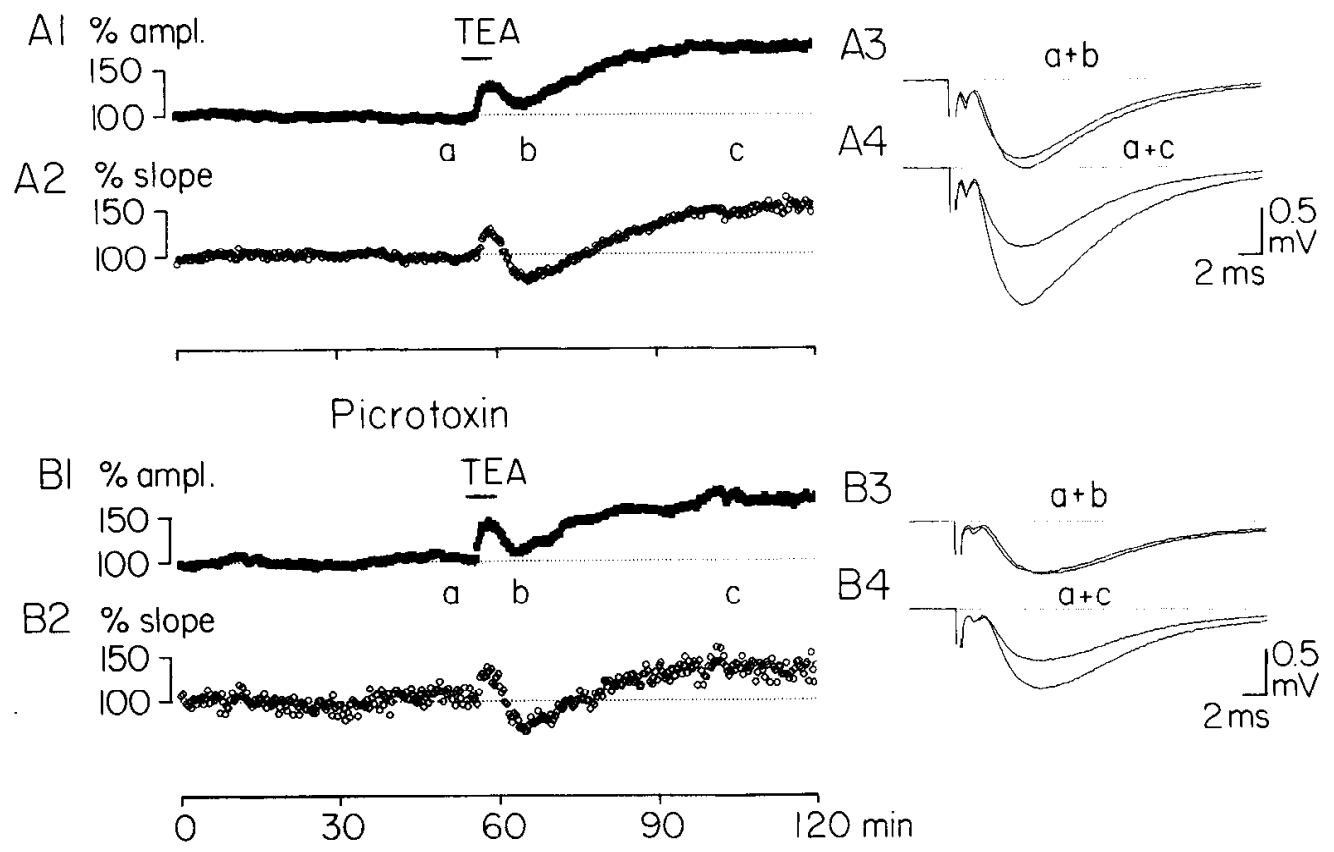

Figure 1. TEA-induced potentiation under normal conditions $(A)$ and during blockade of $\mathrm{GABA}_{\mathrm{A}}$-mediated inhibition $(B) . A 1$ and $A 2$, Measurements of the peak amplitude $(A I)$ and initial slope $(A 2)$ of the field EPSPs are shown from one experiment for a series of responses evoked at $0.5 \mathrm{~Hz}$. TEA $(25 \mathrm{~mm})$ was applied to the perfusion line for 6 min as indicated by the bar. $A 3$ and $A 4$, Average $(n=20)$ records taken at times indicated in $A 1 / 2(a-c) . B$, Same as $A$, but $100 \mu \mathrm{M}$ picrotoxin was present during the experiment.

inputs projecting to the same dendritic region. The two inputs were alternately stimulated at $0.5 \mathrm{~Hz}$ each. Test stimulation intensity was set to elicit a field EPSP initial slope that was about half that which just generated a population spike (measured in the cell body layer). Data were collected and analyzed on line (10 kHz sampling rate) using a 486 PC computer. The magnitude of the field EPSP was evaluated as initial slope, peak amplitude, and area (during $25 \mathrm{msec}$ from EPSP onset), respectively. Area measurements gave essentially the same result as peak amplitude measurements and are therefore not presented. Field EPSP measurements were normalized with respect to the baseline and presented as the average of five consecutive measurements. The initial slope was measured using linear rcgression of the first $0.6 \mathrm{msec}$ just succeeding the presynaptic volley. LTP was induced by five 20 impulse trains at $50 \mathrm{~Hz}$ (intertrain interval, $10 \mathrm{sec}$ ) repeated twice with a few minutes interval. Stimulation intensity during these trains was set to the value at which a single stimulus just evoked a population spike. The values for LTP magnitude given in the Results were taken 15-25 min after the last tetanus. The values for the magnitude of the TEA-induced potentiation were taken 40-50 min after the onset of washout of TEA. Average values are given as mean \pm SEM. Statistical significance for paired samples was evaluated using two-tailed Student's $t$ test.

Picrotoxin, flunarazine, nifedipine, and tetraethylammonium chloride (TEA) were obtained from Sigma; $\mathbf{D}(-)$-2-amino-5-phosphonopentanoic acid (D-AP5) was obtained from Tocris Neuramin. Drugs were applied to the perfusion line. Flunarazine and nifedipine were dissolved in ethanol (final concentration in the perfusion fluid $0.1 \%$, $\mathrm{v} / \mathrm{v}$ ) and were protected from light.

\section{Results}

\section{Effect of TEA application on the field EPSP}

In agreement with previous studies (Aniksztejn and Ben-Ari, 1991; Huang and Malenka, 1993) a brief (6 min) application of $25 \mathrm{~mm}$ TEA was followed by a prolonged potentiation in the amplitude and initial slope of the field potential (Fig. 1 $A$ ). The slow development of the potentiation after the washout of the drug was, at least partly, attributed to a transient ( $<30 \mathrm{~min}$ ) reduction of the presynaptic volley and a delay in the onset of the field potential (Fig. $1 A 3, B 3$; see also Huang and Malenka, 1993). When measured after the end of these transient changes (40-50 min after the onset of TEA washout) the field potential peak amplitude was increased on average by $53 \%$ (Table 1); however, the increase in initial slope was only $15 \%$ (Table 1 ). This result indicates that TEA induced an asymmetric increase in the field potential, a given initial slope now associated with a $34 \%(153 / 115)$ greater amplitude. This discrepancy in initial slope and peak amplitude potentiation was observed also in the presence of picrotoxin $(100 \mu \mathrm{M})$ in the perfusion fluid (Fig. $1 B$, Table 1), and was thus not related to alterations in $\mathrm{GABA}_{\Lambda}$ ergic inhibition. Nevertheless, in the following the experiments

Table 1. TEA-induced potentiation in normal solution, in picrotoxin $(100 \mu \mathrm{M})$, in picrotoxin + D-AP5 $(50 \mu \mathrm{M})$, and in picrotoxin + nifedipine $(20 \mu \mathrm{M})$ /flunarazine $(30 \mu \mathrm{M})$

\begin{tabular}{llll} 
& Initial slope & Peak amplitude & Amplitude/slope \\
\hline Normal solution $(n=6)$ & $115.1 \pm 3.4$ & $152.7 \pm 6.6$ & $1.34 \pm 0.09$ \\
Picrotoxin $(n=9)$ & $122.6 \pm 4.1$ & $144.9 \pm 4.3$ & $1.19 \pm 0.03$ \\
$\begin{array}{l}\text { Picrotoxin + D-AP5 }(n=5) \\
\text { Picrotoxin + nifedipine/ }\end{array}$ & $102.4 \pm 1.5$ & $145.2 \pm 7.7$ & $1.42 \pm 0.08$ \\
$\quad$ flunarazine $(n=11)$ & $164.6 \pm 6.0$ & $160.0 \pm 7.2$ & $0.97 \pm 0.02$ \\
\hline
\end{tabular}




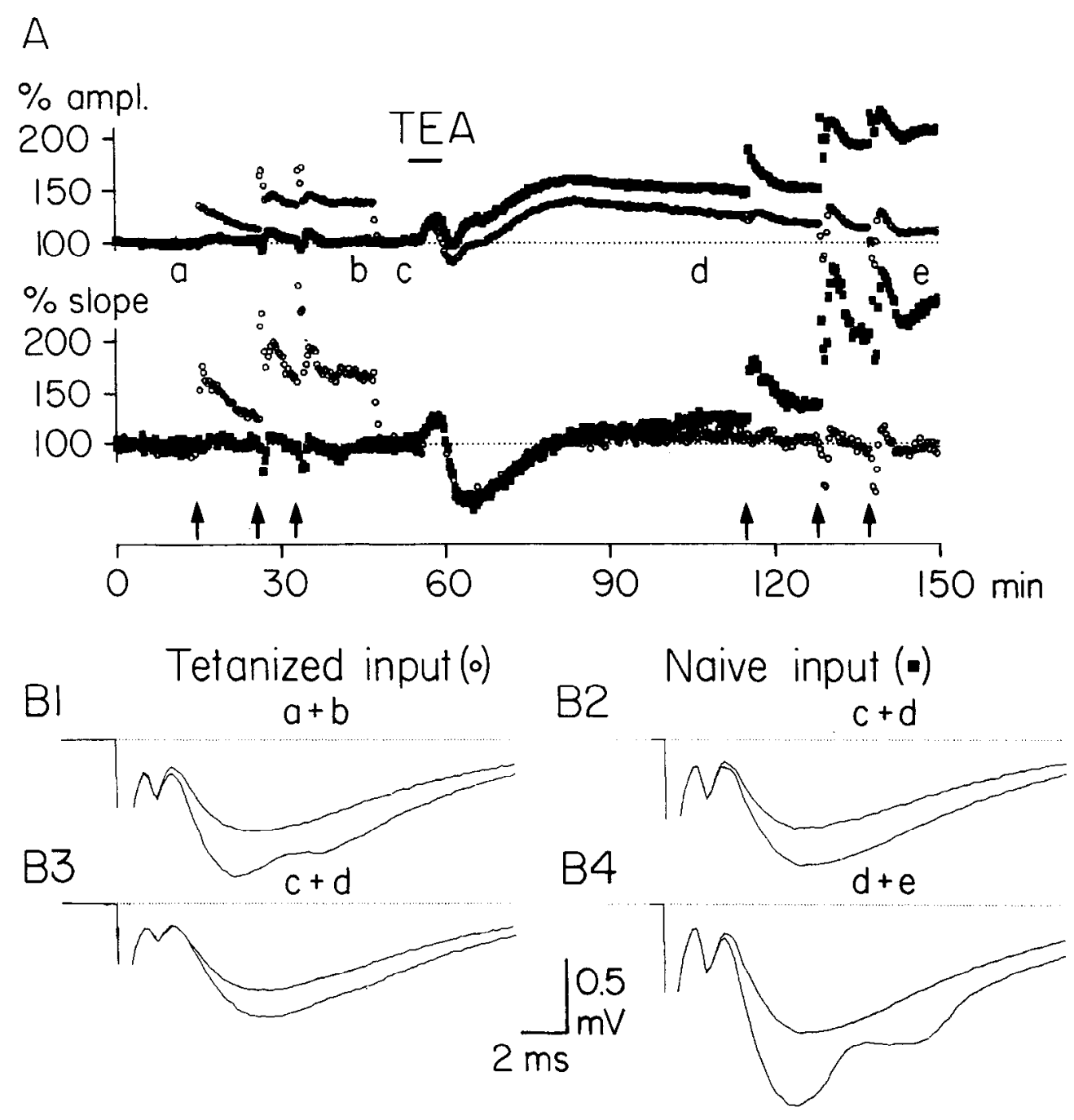

Figure 2. Interaction between tetanus-induced LTP and TEA-induced potentiation. $A$, Measurements of the peak amplitude (upper graph) and initial slope (lower graph) of the field EPSPs are shown from one experiment for a series of responses evoked at $0.5 \mathrm{~Hz}$ alternately to the test input (open circles) and to the control input (solid squares). Picrotoxin $(100 \mu \mathrm{M})$ was present throughout the experiment. Three series of tetanizations $(50 \mathrm{~Hz}$, indicated by arrows) were delivered to the test input before the application of TEA (first three arrows), and to the control input after the application of TEA (last three arrows). The first tetanization to each input was a 10 impulse tetanus, the second and third sets of tetanizations to each input were five 20 impulse tetani spaced at $10 \mathrm{sec}$. The test input stimulus intensity was reduced before the application of TEA so that the field EPSPs evoked by the test and control input were of approximately the same magnitude; $25 \mathrm{~mm}$ TEA was applied to the perfusion line for $6 \mathrm{~min}$ as indicated by the bar. In this experiment the field EPSP initial slope and amplitude of the test input were $109 \%$ and $133 \%$ of control, respectively, $40 \mathrm{~min}$ after the washout of TEA, and the corresponding values for the control input were $129 \%$ and $149 \%$, respectively. $B$, Average $(n$ $=20$ ) records of the test and control field EPSPs taken at times indicated in $A(a-e)$.

were performed with $100 \mu \mathrm{M}$ picrotoxin in the perfusion fluid in order to analyze the field EPSP in isolation.

\section{Effect of TEA application on a previously tetanized input}

The asymmetric increase in the field EPSP following TEA application contrasts with the symmetrical increase in the field EPSP that is associated with tetanus-induced LTP (Abraham et al., 1987; Asztely and Gustafsson, 1994), suggesting that TEAinduced potentiation contains components that differ from tetanus-induced LTP. In nine experiments one of the two inputs projecting to the same dendritic region was therefore repeatedly tetanized prior to the TEA application. This prior tetanization caused a smaller TEA-induced potentiation in the field EPSP amplitude, and entirely abolished the potentiation in the field EPSP initial slope (Fig. 2A, Table 2). On the other hand, the asymmetric change in the field EPSP induced by the TEA application was unaffected by the prior tetanization (Table 2). This finding indicates that TEA induces a potentiation component that is distinct from tetanus-induced LTP.

The previously untetanized control input was subsequently (50-60 min after the onset of TEA washout) subjected to the same repeated tetanization as the test input (Fig. $2 A$ ). These

Table 2. Interaction between TEA-induced potentiation and tetanus-induced LTP in the presence of picrotoxin $(100 \mu \mathrm{M})$

\begin{tabular}{lccc} 
& Initial slope & Peak amplitude & Amplitude/slope \\
\hline Test input & $101.6 \pm 4.6$ & $124.2 \pm 7.6$ & $1.22 \pm 0.03$ \\
Control input & $122.6 \pm 4.1$ & $144.9 \pm 4.3$ & $1.19 \pm 0.03$ \\
Paired difference & $21.0 \pm 4.4$ & $20.7 \pm 7.8$ & $-0.03 \pm 0.05$ \\
$p$ & $<0.01$ & $<0.05$ & $>0.05$ \\
\hline
\end{tabular}

Values are given as percentage of baseline \pm SEM. Before application of TEA the test input was tetanized, resulting in an a verage increase of the field EPSP initial slope to $196.6 \pm 10.4 \%$. The control input was tetanized after the establishment of the TEA-induced potentiation, which resulted in an increase to $192.4 \pm 14.5 \%, p>0.05, n=9$. 


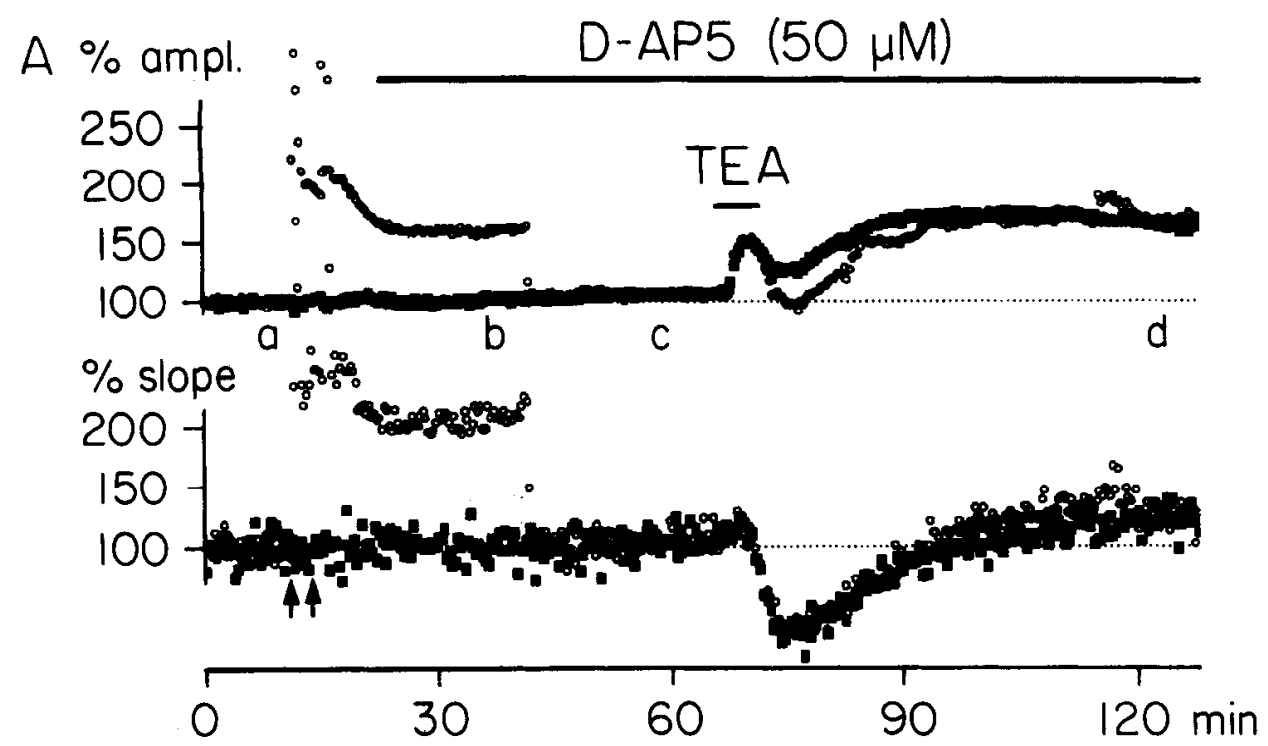

Tetanized input ( $(\circ)$

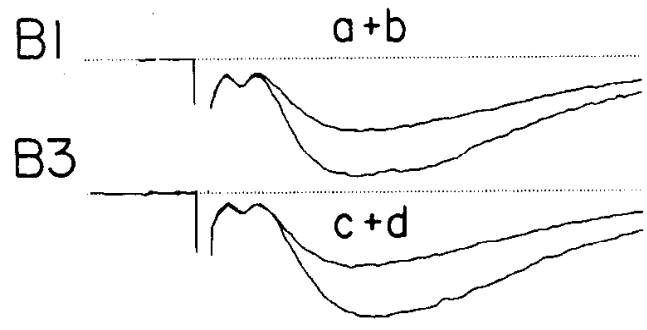

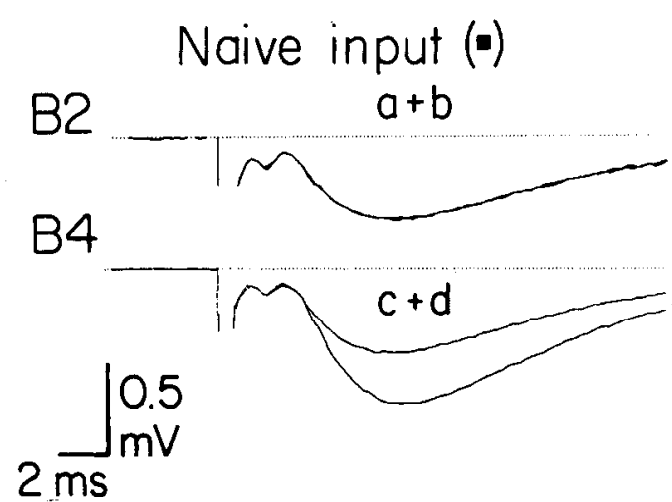

Figure 3. D-AP5 blocks one component of the TEA-induced potentiation. $A$, Measurements of the peak amplitude (upper graph) and initial slope (lower graph) of the field EPSPs are shown from one experiment for a series of responses evoked at $0.5 \mathrm{~Hz}$ alternately to the test inpul (open circles) and to the control input (solid squares). Picrotoxin $(100 \mu \mathrm{M})$ was present throughout the experiment. letanizations (five 20 impulse trains at $50 \mathrm{~Hz}$, intertrain interval, $10 \mathrm{sec}$ ) were delivered at times indicated by arrows. The test input stimulus intensity was reduced before the application of TEA so that the field EPSPs evoked by the test and control input were of approximately the same magnitude; $25 \mathrm{~mm}$ TEA was applied to the perfusion line for $6 \mathrm{~min}$ as indicated by the bar. In this experiment the field EPSP initial slope and amplitude of the test input were $98 \%$ and $157 \%$ of control, respectively, $40 \mathrm{~min}$ after the washout of TEA, and the corresponding values for the control input were $104 \%$ and $171 \%$, respectively. $B$, Average ( $n$ $=20$ ) records of the test and control field EPSPs taken at times indicated in $A(a-d)$. inputs became potentiated to much the same extent as the inputs tetanized prior to the TEA application $(92.4 \%$ vs $96.6 \%, p>$ $0.05, n=9$ ).

\section{$T E A$-induced potentiation in the presence of an NMDA antagonist}

The above results suggest that TEA induces two distinct potentiations, one of which appears to be equal to tetanus-induced LTP. The question then arises whether this component of the TEA-induced potentiation is induced via activation of NMDA receptors, as is tetanus-induced $\mathrm{LTP}$, or via some other route. To examine this question the same experiment as above was performed, with the exception that D-AP5 was added to the perfusion fluid in between the tetanization of the test input and the TEA application. Figure 3 (from one such experiment) and
Table 3 show that under these conditions none of the inputs showed any significant TEA-induced potentiation in the initial slope. This result supports the notion that the TEA-induced potentiation in the initial slope is mediated via activation of NMDA receptors. Moreover, there was no significant difference in TEA-induced potentiation of the peak amplitude betwecn the two inputs (Table 2), demonstrating that the asymmetric potentiation of the field EPSP induced by TEA is distinct from NMDA receptor-dependent tetanus-induced LTP.

\section{$T E A$-induced potentiation in the presence of voltage-dependent calcium channel antagonists}

Previous studies (Anikszlejn and Ben-Ari, 1991; Huang and Malenka, 1993) have reported that TEA-induced potentiation is largely blocked by flunarazine and nifedipine, indicating an

$\begin{aligned} & \text { Table 3. Interaction between TEA-induced potentiation and tetanus-induced LTP in the presence of } \\ & \text { D-AP5 }\end{aligned}$
\[ \begin{array}{lcc} \\ \end{array} \]

Picrotoxin (100 $\mu \mathrm{M})$ was present during the experiments. Values are given as percentage of baseline \pm SEM. Before application of TEA the test input was tetanized, resulting in an average increase of the field EPSP initial slope to 210 $\pm 11.2 \%(n=5)$. 

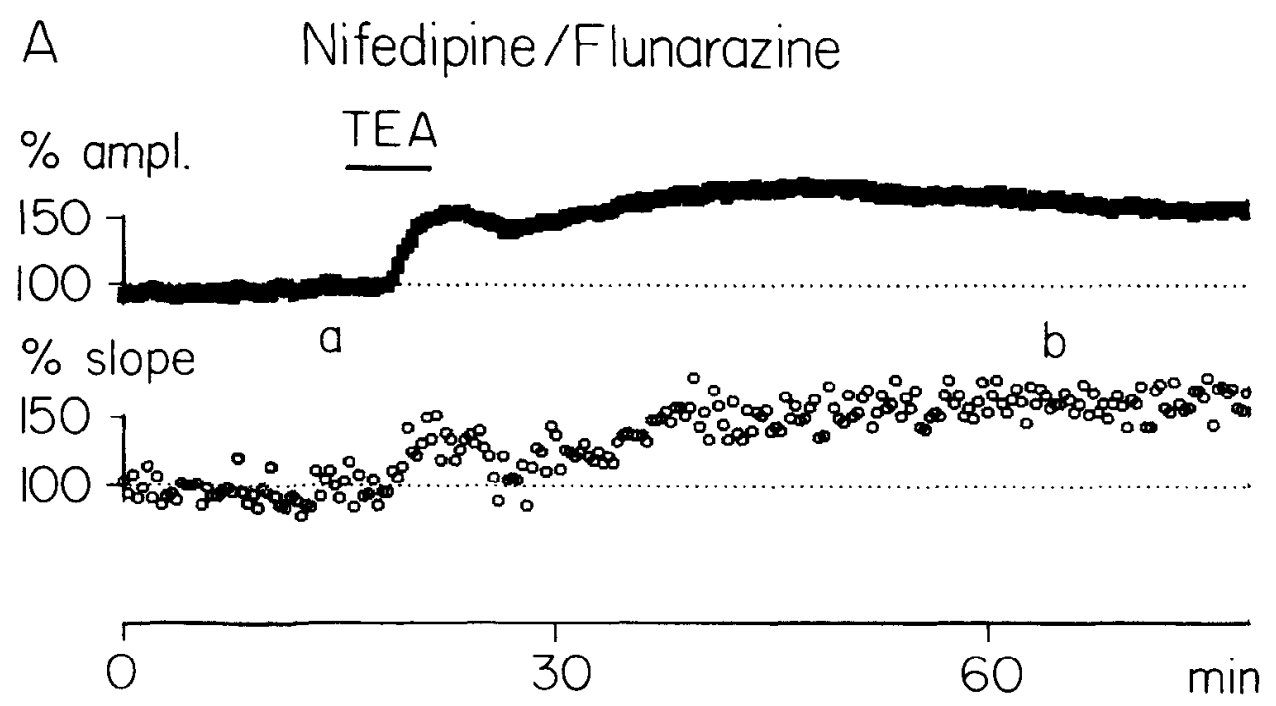

Figure 4. TEA-induced potentiation in the presence of antagonists to voltage-dependent calcium channels. $A$, Measurements of the peak amplitude (upper graph) and initial slope (lower graph) of the field EPSPs are shown from one experiment for a series of responses evoked at $0.5 \mathrm{~Hz}$. Picrotoxin $(100 \mu \mathrm{M})$ was present throughout the experiment; $25 \mathrm{~mm}$ TEA was applied to the perfusion line for $6 \mathrm{~min}$ as indicated by the bar. $B$, Average $(n=20)$ records of the test and control field EPSPs taken at times indicated in $A$ ( $a$ and $b$ ).

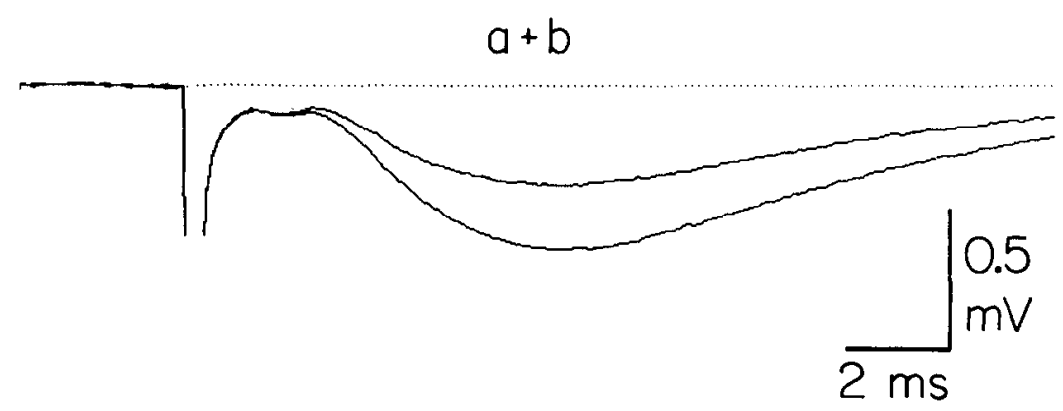

involvement of voltage-dependent calcium channels in its induction. Under the present conditions TEA evoked a substantial prolonged potentiation also in the presence of either $20 \mu \mathrm{M}$ nifedipine or the combination of $20 \mu \mathrm{M}$ nifedipine and $30 \mu \mathrm{M}$ flunarazine (Fig. 4, Table 4). Figure $4 B$ and Table 4 show that this potentiation was associated with an about equal increase of field EPSP initial slope and amplitude, that is, a symmetrical increase in the field EPSP. As also shown in Table 4, the TEAinduced potentiation under these conditions was substantially reduced for inputs that had been tetanized prior to the TEA application.

\section{Discussion}

The present results suggest that the prolonged potentiation that follows a transient application of TEA is partially based on induction/expression mechanisms that are distinct from those underlying tetanus-induced LTP. The results support the notion that calcium ions through NMDA receptor channcls have a privileged role in inducing NMDA receptor-dependent LTP. A corollary to this is that the prolonged potentiation induced by opening of voltage-dependent calcium channels is based on an expression mechanism distinct from NMDA receptor-dependent LTP.

The study of Aniksztejn and Ben-Ari (1991) showed that an LTP could be produced in a manner that bypasses the NMDA receptor channels. This notion was based on the finding that the generation of TEA-induced potentiation was unaffected by the presence of an NMDA receptor antagonist but was blocked by an antagonist to voltage-dependent calcium channels. Occlusion experiments to demonstrate whether this TEA-induced potentiation used the same expression mechanisms as NMDA receptor-dependent LTP was however not reported. More recently, occlusion experiments have indicated that TEA-induced potentiation and tetanus-induced LTP should share expression mechanisms, suggesting that NMDA receptor-dependent LTP indeed could be generated via calcium influx through voltagedependent calcium channels (Huang and Malenka, 1993).

In general agreement with this latter study, the present one showed that TEA-induced potentiation was smaller in a previously tetanized input than in a naive one, indicating shared mechanisms. However, several findings suggest that this result might not necessarily be taken as evidence that NMDA receptor-dependent LTP can be evoked via calcium influx through voltage-dependent calcium channels. First, the result that TEAinduced potentiation was smaller in a previously tetanized input than in a naive one was not observed when TEA was applied in the presence of an NMDA receptor antagonist. This result implies that the partial occlusion between the TEA-induced potentiation and the tetanus-induced one (in the absence of an NMDA receptor antagonist) is related to the fact that TEA also induces potentiation via activation of NMDA receptor channels. Second, the finding of a similar magnitude of TEA-induced potentiation (in the presence of an NMDA receptor antagonist) in previously telanized and naive inputs demonstrates that the TEA-induced potentiation uses an expression mechanism that is distinct from that underlying NMDA receptor-dependent LTP.

In agreement with the result that a component of the TEA- 


\begin{tabular}{|c|c|c|c|}
\hline & Initial slope & Peak amplitude & Amplitude/slope \\
\hline Test input & $120.8 \pm 5.5$ & $124.8 \pm 5.8$ & $1.03 \pm 0.02$ \\
\hline Control input & $177.8 \pm 7.2$ & $176.2 \pm 7.7$ & $0.99 \pm 0.03$ \\
\hline Paired difference & $62.8 \pm 13.5$ & $51.4 \pm 9.4$ & $0.01 \pm 0.02$ \\
\hline$p$ & $<0.01$ & $<0.01$ & $>0.05$ \\
\hline
\end{tabular}

Picrotoxin $(100 \mu \mathrm{M})$ was present during the experiments. Values are given as percentage of baseline \pm SEM. Before application of TEA the test input was tetanized, resulting in an average increase of the field EPSP initial slope to 213.2 $\pm 17.0 \%$. The control input was tetanized after the establishment of the TEA-induced potentiation, which resulted in an increase to $150.4 \pm 7.2 \%, p>0.05, n=5$.

induced potentiation was generated via NMDA receptor channel activation, a potentiation induced by TEA was also observed in the presence of antagonists to voltage-dependent calcium channels. This result contrasts with those of Aniksztejn and BenAri (1991) and Huang and Malenka (1993), who found no significant potentiation in the presence of these antagonists. The TEA-induced potentiation presently observed in the presence of calcium channel antagonists was largely occluded by prior induction of tetanus-induced LTP, suggesting that it was indeed evoked via NMDA receptor activation. Moreover, this occlusion suggests, in agreement with Aniksztejn and Ben-Ari (1991) and Huang and Malenka (1993), that the TEA-induced potentiation (that does not interact with tetanus-induced LTP) is mediated via activation of voltage-dependent calcium channels. We have no explanation for the discrepancy regarding the ahility of TEA to activate NMDA receptor channels except that the higher test stimulus rate and the presence of picrotoxin might have facilitated the activation of NMDA receptor channels (during the TEA application) in the present study (cf. Aniksztejn and Ben-Ari, 1991).

If, as suggested by the present results, the TEA-induced potentiation consists of two components, one might expect that the potentiation observed in the absence of any blocker would at least be the sum of that observed in the presence of antagonists to the NMDA receptor and the voltage-dependent calcium channels, respectively. However, this was not the case (compare Table 1). A tentative explanation for this behavior would be that the presence of one antagonist facilitates the induction conditions via the other route. In fact, calcium channel antagonists have been shown to cause increased synaptic activity in the hippocampal slice preparation (O'Regan et al., 1991). On the other hand, it less clear in what manner an NMDA receptor antagonist could facilitate activation of voltage-dependent calcium channels.

In support of the above notion, based on occlusion experiments and pharmacology, that TEA induces two separate potentiations using different expression mechanisms, the present analysis showed that TEA induces two different modifications of the field EPSP. One modification is associated with a symmetrical increase in the field EPSP (as is NMDA receptor-dependent LTP; Abraham et al., 1987; Asztely and Gustafsson, 1994), and the other one is asymmetric, the initial slope being much less affected than the remaining part of the field EPSP. This second component was not observed in the presence of calcium channel antagonists, and was the only onc present in inputs that had been subjected to tetanization prior to the TEA application and when NMDA receptor antagonists was present. These results suggest that calcium influx through voltage-de- pendent calcium channels causes a synaptic modification of a different nature than that caused by calcium influx through NMDA receptor channels. Some evidence for synaptic potentiations in the CAl region using different expression mechanisms have been obtained also previously. Thus, application of NMDA produces a potentiation with two components, one that is occluded by prior tetanization (and related to an increase in the early part of the field EPSP), and one that is unaffected by prior tetanization (and does not affect the initial slope of the field EPSP) (Asztely et al., 1991). Whether this latter component is identical to that presently observed following TEA application, is induced via activation of voltage-dependent calcium channels (by the depolarization generated by synaptic NMDA receptor activation) or via some other route, remains to be examined. Hess and Gustafsson (1990) and Hanse et al. (1991) (in the dentate gyrus) have also reported that strong tetanization, in addition to LTP, can induce a field EPSP modification resembling that seen following TEA (and NMDA) application. Again evidence is lacking for the direct involvement of voltage-dependent calcium channels in the induction of this potentiation. Kullman et al. (1993) and Kato et al. (1993) have demonstrated a potentiation mediated via activation of voltagedependent calcium channels. In the report by Kullman et al. (1993) this (transient) potentiation was unaffected by prior induction of tetanus-induced LTP, indicating separate mechanisms. Grover and Teyler (1990a,b) have shown that high-frequency $(\geq 200 \mathrm{~Hz})$ afferent activation in the presence of an NMDA receptor antagonist produces a prolonged potentiation that is much reduced in the presence of antagonists to voltagedependent calcium channels. Whether this potentiation is occluded by prior induction of NMDA receptor-dependent LTP and is associated with an asymmetric modification of the field EPSP remains to be examined. It is, however, noteworthy that this NMDA independent potentiation, compared to the NMDA receptor-dependent one, was more evident for the population spike than for the field EPSP initial slope (cf. Grover and Teyler, 1990b, their Fig. 2).

As outlined in the introductory section the present study was focused on the question whether calcium influx through voltagedependent calcium channels produces the same type of potentiation as calcium influx through NMDA receptor channels, as indicated by earlier studies using TEA application to induce LTP. The present results suggest that the LTP produced by TEA application via voltage-dependent calcium channels is distinct from NMDA receptor-dependent LTP, bcing bascd on a different type of synaptic modification. As is the case for NMDA receptor-dependent $L T P$, the nature and location, pre- or postsynaptic, of this modification is presently unknown. 


\section{References}

Abraham WC, Gustafsson B, Wigström H (1987) Long-term potentiation involves enhanced synaptic excitation relative to synaptic inhibition in guinea-pig hippocampus. J Physiol (Lond) 394:367-380.

Aniksztejn L, Ben-Ari Y (1991) Novel form of long-term potentiation produced by a $\mathrm{K}^{+}$channel blocker in the hippocampus. Nature 349 : 67-69.

Asztely F, Gustafsson B (1994) Dissociation between long-term potentiation and associated changes in field epsp waveform in the hippocampal CAl region. Hippocampus 4:1-9.

Asztely F, Hanse E, Wigström H, Gustafsson B (1991) Synaptic potentiation in the hippocampal CAl region induced by application of $N$-methyl-D-aspartate. Brain Res 558:153-156.

Grover LM, Teyler TJ (1990a) Two components of long-term potentiation induced by different patterns of afferent activation. Nature $347: 477-479$.

Grover LM, Teyler TJ (1990b) Differential effects of NMDA receptor antagonist APV on tetanic stimulation induced and calcium induced potentiation. Neurosci Lett 113:309-314.

Gustafsson B, Asztely F, Hanse E, Wigström H (1989) Onset characteristics of long-term potentiation in the guinea-pig hippocampal CA1 region in vitro. Eur I Neurosci 1:382-394.

Hanse E, Asztely F, Wigström H, Gustafsson B (1991) Long-lasting potentiations evoked by heterosynaptic tetani in the guinea pig dentate gyrus in vitro. Brain Res 555:173-176.

Hess G, Gustafsson B (1990) Changes in field excitatory postsynaptic potential shape induced by tetanization in the CAl region of the guinea-pig hippocampal slice. Neuroscience 37:61-69.

Huang Y-Y, Malenka RC (1993) Examination of TEA-induced synaptic enhancement in area CA1 of the hippocampus: the role of voltage-dependent $\mathrm{Ca}^{2+}$ channels in the induction of LTP. J Neurosci 13: 568-576.

Kato K, Clifford DB, Zorumski CF (1993) Long-term potentiation during whole-cell recording in rat hippocampal slices. Neuroscience 53:39-47.

Kullmann DM, Perkel DJ, Manabe T, Nicoll RA (1992) $\mathrm{Ca}^{2+}$ entry via postsynaptic voltage-sensitive $\mathrm{Ca}^{2+}$ channels can transiently potentiate excitatory synaptic transmission in the hippocampus. Neuron 9:1175-1183.

Madison DV, Malenka RC, Nicoll RA (1991) Mechanisms underlying long-term potentiation of synaptic transmission. Annu Rev Neurosci 14:379-397.

O’Regan MH, Kocsis JD, Waxman SG (1991) Nimodipine and nifedipine enhance transmission at the Schaffer collateral CAl pyramidal neuron synapse. Exp Brain Res 84:224-228. 